\title{
Qualidade de frutos de tomate 'giuliana' tratados com produtos de efeitos fisiológicos
}

\author{
Fruit quality of tomato 'giuliana' treated with products with \\ physiological effects
}

\author{
Anamaria Ribeiro Pereira Ramos ${ }^{1 *}$; Amanda Cristina Esteves Amaro ${ }^{1}$; \\ Ana Claudia Macedo ${ }^{1}$; Guilherme Shigueyuki de Assis Sugawara ${ }^{1}$; \\ Regina Marta Evangelista2 ${ }^{2}$ João Domingos Rodrigues²,3; Elizabeth Orika Ono ${ }^{2,3}$
}

\section{Resumo}

O trabalho avaliou o efeito de estrobilurinas, boscalida, reguladores e extratos vegetais na qualidade físico-química de frutos de tomateiro (Solanum lycopersicum L.), híbrido Giuliana. Os frutos de cada tratamento foram selecionados e separados em 4 repetições: testemunha, piraclostrobina, boscalida, piraclostrobina + boscalida, IBA $+\mathrm{GA}_{3}+$ cinetina, $\mathrm{GA}_{4+7}+$ benzilaminopurina e extrato vegetal. A primeira aplicação foi realizada 30 dias após o transplantio e as demais, a cada 15 dias. As avaliações foram: perda de massa, acidez titulável (AT), sólidos solúveis (SS), relação $\mathrm{SS} / \mathrm{AT}, \mathrm{pH}$, teor de ácido ascórbico, textura, açúcares solúveis totais (AST), atividade da pectinametilesterase (PME) e poligalacturonase (PG). O teor de SS, responsável pelo sabor do fruto, variou em função dos tratamentos, sendo o maior para $\mathrm{GA}_{4+7}+$ benzilaminopurina e o menor para a testemunha. O mesmo aconteceu com a relação SS/AT. Os frutos permaneceram por 9 dias em bancada, em temperatura ambiente e ao final desse tempo, alguns tratamentos ainda apresentavam frutos ótimos para o consumo, destacandose o tratamento com boscalida, que apresentou menor perda de massa, seguido pela piraclostrobina. Assim, pode-se concluir que a aplicação dos tratamentos não alterou os valores de $\mathrm{pH}$, AT e AST dos frutos. Notou-se maior atividade da PME nos tratamentos com boscalida e com a mistura de boscalida e piraclostrobina, ao mesmo tempo, se constatou menor atividade da PG nos tratamentos testemunha e piraclostrobina, indicando que alguns produtos aceleraram o processo de desmetilação das pectinas pela PME, facilitando a ação da PG.

Palavras-chave: Solanum lycopersicum, estrobilurinas, boscalida, reguladores vegetais, pós-colheita

\begin{abstract}
The present work evaluated the effect of strobilurins, boscalid, plant growth regulators and vegetal extracts on the physico-chemical quality of tomato fruits (Solanum lycopersicum L.), hybrid Giuliana. The fruits from each treatment were selected and separated in 4 repetitions: control, pyraclostrobin, boscalid, pyraclostrobin + boscalid, IBA $+\mathrm{GA}_{3}+$ kinetin, $\mathrm{GA}_{4+7}+$ benzylaminopurine and vegetal extract. The first application was carried out at 30 days after transplant and the following at every 15 days. The evaluations were: weight loss, titratable acidity (TA), soluble solids (SS), SS/TA relation, $\mathrm{pH}$,
\end{abstract}

\footnotetext{
${ }^{1}$ Discentes do Dept ${ }^{\circ}$ de Produção Vegetal, Horticultura, Universidade Estadual Paulista "Júlio de Mesquita Filho", Faculdade de Ciências Agronômicas, UNESP, Campus Botucatu, Botucatu, SP. E-mail: anamaria-ramos@oi.com.br; amandaamaro@uol.com. br; anamacedo85@gmail.com; gsdasugawara@fca.unesp.br

2 Prof. do Dept ${ }^{\circ}$ de Produção Vegetal, Horticultura, UNESP, Faculdade de Ciências Agronômicas, Campus Botucatu, Botucatu, SP. E-mail: evangelista@fca.unesp.br

${ }^{3}$ Profs. do Dept ${ }^{\circ}$ de Botânica, UNESP, Instituto de Biociências, Campus Botucatu, Botucatu, SP. E-mail: mingo@ibb.unesp.br; eoono@ibb.unesp.br

* Autor para correspondência
} 
ascorbic acid content, texture, total soluble sugars (TSS), activity of pectin methyl esterase (PME) and polygalacturonase (PG). The SS content, responsible for fruit flavor, varied accordingly to the treatment, being highest for $\mathrm{GA}_{4+7}+$ benzylaminopurine and lowest for the control. The same occurred regarding the SS/AT relation. The fruits were kept on the shelf for 9 days, at room temperature, being that at the end of this period several treatments still presented fruit in optimal consumption conditions, notably the boscalid treatment, which presented lowest weight loss, followed by pyraclostrobin. Therefore, it can be concluded that the application of the treatments did not modify the values for $\mathrm{pH}$, AT and AST of the fruits. The highest PME activity was observed for the treatments with boscalid and the mixture of boscalid and pyraclostrobin, while the lowest PG activity occurred in the control and the pyraclostrobin treatment, indicating that some products accelerated the process of demethylation of pectins by PME, facilitating the action of PG.

Key words: Solanum lycopersicum, strobilurins, boscalid, plant growth regulators, postharvest, plant extract

\section{Introdução}

A produção de frutos de tomateiro (Solanum lycopersicum L.) pode ser voltada para a indústria (processados) e/ou para o consumo in natura. Os tomateiros são subdivididos em cinco grupos, dentre estes encontra-se o grupo italiano, cujos frutos são recomendados tanto para o consumo in natura, como para a indústria. Os frutos de tomate de cultivares deste grupo caracterizam-se por serem alongados, biloculares, com polpa espessa, coloração vermelha intensa, firmes e saborosos (FILGUEIRA, 2003; ALVARENGA, 2004).

Embora a produção de tomate ocorra em todas as regiões do país e em diferentes épocas do ano, a sazonalidade da oferta e dos preços ocorre em grandes centros e as estimativas de perdas pós-colheita de tomate são superiores a $30 \%$, especialmente por deterioração fisiológica, desenvolvimento de doenças e danos mecânicos (LUENGO et al., 2001). Assim, o controle do processo de amadurecimento dos frutos de tomate, aumentando seu tempo de comercialização, pode melhorar a distribuição dessa hortaliça para diferentes regiões do país e diminuir as perdas pós-colheita. Um dos grandes desafios da horticultura é melhorar a qualidade, aumentar a vida útil do produto e diminuir as perdas pós-colheita (JUNQUEIRA; LUENGO, 2000; VILELA; MACEDO, 2000).

Um importante manejo em frutos é retardar o amadurecimento e a senescência e proporcionar textura mais firme dos frutos, conferindo-lhes maior resistência aos danos de natureza fisiológica, microbiana e mecânica, aumentando seu tempo de prateleira. Alguns produtos podem reduzir a respiração de frutos climatéricos, como o 1-MCP aplicado nos frutos do tomateiro (BRACKMANN et al., 2009), atrasando o processo de amadurecimento de frutos.

Já foi evidenciado o papel dos reguladores vegetais, principalmente, as giberelinas no amadurecimento de frutos, os quais têm sido estudados como retardadores da senescência. $\mathrm{O}$ ácido giberélico tem sido utilizado em limões e tomates para a melhoria da qualidade e aparência no armazenamento (CHITARRA; CHITARRA, 2005). A aplicação exógena de giberelina permite retardar o aparecimento da coloração vermelha em tomate e a maturação em banana e caqui (TAIZ; ZEIGER, 2009).

Extratos vegetais contendo citocininas foram obtidos de mais de 50 espécies e os níveis mais altos são encontrados em tecidos onde ocorre a divisão celular (TAIZ; ZEIGER, 2009). O produto utilizado é um estimulante vegetal composto de extratos de Agave (Yucca shidigera) e micronutrientes minerais com ação semelhante às citocininas (SOUZA LEÃO; SILVA; SILVA, 2005).

No início dos anos 80 observou-se que o fungo Strobiluros tenacellus produzia uma substância, denominada de estrobilurina, que apresentava ação 
antifúngica. Com a utilização dessa substância como fungicida, observou-se também que, estas moléculas atuavam de forma positiva sobre a fisiologia das plantas, por meio da diminuição da respiração e da redução da produção de etileno, o que pode influenciar a qualidade pós-colheita (KÖHLE et al., 1994). A estrobilurina possui efeito, também, na síntese de etileno em condições de estresse e senescência no trigo, por meio da redução da atividade da enzima ácido aminociclopropanocarboxílico-sintase (ACC-sintase) inibindo a síntese de etileno (GROSSMANN, RETZLAFF, 1997; YPEMA, GOLD, 1999), sendo assim podem também, inibir a síntese de etileno nos frutos, retardando, principalmente, o amadurecimento de frutos climatéricos.

O boscalida é um fungicida pertencente à família das carboxamidas e ao grupo químico das anilidas e possui os mesmos efeitos das estrobilurinas, além de fornecer proteção antifúngica preventiva da planta.

Visando atender as exigências do mercado, visto que o consumidor requer frutos onde a aparência, ou seja, tamanho, ausência de defeitos, firmeza e coloração são os atributos de qualidade mais procurados, este trabalho teve como objetivo avaliar o efeito da aplicação de estrobilurina, boscalida, reguladores vegetais e extrato vegetal na qualidade física e química de frutos de tomateiro (Solanum lycopersicum L.) híbrido Giuliana, cultivados em ambiente protegido.

\section{Material e Métodos}

O experimento foi conduzido em ambiente protegido na área experimental da Fazenda de Ensino, Pesquisa e Produção de São Manuel, município de São Manuel - SP, pertencente à Faculdade de Ciências Agronômicas, Campus de Botucatu, da Universidade Estadual Paulista UNESP, no período de julho a dezembro de 2010 em ambiente protegido.
Os tratamentos avaliados foram: T1-testemunha; T2- piraclostrobina $\left(0,2 \mathrm{~g} \mathrm{~L}^{-1}\right)$; T3- boscalida $(0,075$ $\left.\mathrm{g} \mathrm{L}^{-1}\right)$; T4- piraclostrobina $\left(0,2 \mathrm{~g} \mathrm{~L}^{-1}\right)+$ boscalida $\left(0,075 \mathrm{~g} \mathrm{~L}^{-1}\right)$; T5- IBA $+\mathrm{GA}_{3}+$ cinetina $(375 \mathrm{mg}$ $\left.\mathrm{L}^{-1}\right)$; T6- $\mathrm{GA}_{4+7}+$ benzilaminopurina $\left(100 \mathrm{mg} \mathrm{L}^{-1}\right) \mathrm{e}$ T7- extrato vegetal $100 \mathrm{mg} \mathrm{L}^{-1}$. Todos os tratamentos com adição de óleo vegetal a $0,5 \%$ no momento da pulverização foliar.

Como fonte de boscalida utilizou-se o produto comercial Cantus $^{\circledR}$ contendo $500 \mathrm{~g} \mathrm{~kg}^{-1}$ do p.a. e para piraclostrobina o produto comercial Comet ${ }^{\circledR}$ contendo $250 \mathrm{~g} \mathrm{~L}^{-1}$ do p.a., ambos da BASF S.A. Como fonte da mistura de ácido indolilbutírico (IBA- auxina), $\mathrm{GA}_{3}$ (giberelina) e cinetina (citocinina) utilizou-se o produto comercial Stimulateâ contendo $90 \mathrm{mg} \mathrm{L}^{-1}$ de cinetina $(\mathrm{Kt})$, $50 \mathrm{mg} \mathrm{L}^{-1}$ de IBA e $50 \mathrm{mg} \mathrm{L}^{-1}$ de $\mathrm{GA}_{3}$ por litro do produto, fabricado pela Stoller do Brasil S.A. Como fonte da mistura de benzil-aminopurina (citocinina) e $\mathrm{GA}_{4}+\mathrm{GA}_{7}$ (giberelinas), o produto comercial Promalin ${ }^{\circledR}$ contendo $1,8 \%$ de $\mathrm{GA}_{4+7}$ e $1,8 \%$ de benzil-aminopurina (BAP) fabricado pela Sumitomo do Brasil. Como fonte do extrato vegetal utilizou-se o produto comercial Crop $\operatorname{Set}^{\grave{O}}$ registrado no Brasil como fertilizante foliar composto por $1,5 \%$ de manganês, $1,5 \%$ de ferro e $1 \%$ de cobre, $\mathrm{e}$ as informações do fabricante indicam que o mesmo é um estimulante vegetal composto de extratos vegetal de agave (Yucca shidigera) com ação semelhante às citocininas (SOUZA LEÃO; SILVA, SILVA, 2005). Em todos os tratamentos foi adicionado o óleo vegetal, Natural'óleo a $0,5 \%$.

A primeira aplicação dos tratamentos foi realizada aos 30 dias após o transplante das mudas, no início do florescimento e as demais, a cada 15 dias. As aplicações dos tratamentos foram realizadas via foliar com o uso de pulverizador manual de $\mathrm{CO}_{2}$ pressurizado, com pressão de $2 \mathrm{kgf} \mathrm{cm}^{-2}$ e vazão de $0,2 \mathrm{~L} \mathrm{~min}^{-1}$, utilizando-se cortina plástica entre os tratamentos para evitar a deriva.

Os frutos de tomateiro híbrido Giuliana foram colhidos de cinco plantas por repetição, em 
novembro de 2010, no pico da produção aos 116 dias após o transplantio (DAT). Transportados para o laboratório de fisiologia pós-colheita do Departamento de Horticultura, da UNESPFCA, Botucatu, SP, lavados em água corrente e selecionados quanto à uniformidade de tamanho, ausência de defeitos, estádio de maturidade e separados em quatro repetições com 12 frutos cada, conforme os tratamentos realizados nas plantas em campo.

Foram separados dois frutos de cada repetição para as análises destrutivas e dez frutos para avaliação de perda de massa, os quais foram divididos em cinco bandejas de isopor $(18 \times 10 \mathrm{~cm})$, onde foram pesados a cada dois dias até o 9ำ dia. Esses frutos foram mantidos sobre bancada do laboratório de fisiologia pós-colheita com temperatura média de $27^{\circ} \mathrm{C}$ e umidade relativa de $60 \%$. Para o cálculo da perda de massa foi utilizada a diferença entre as pesagens em cada intervalo de tempo e os resultados foram expressos em porcentagem (\%). Foram mantidos no laboratório o mesmo delineamento e identificação do campo, com quatro repetições e sete tratamentos inteiramente casualizados, e os resultados foram submetidos à análise de variância e as médias comparadas pelo teste Tukey $(p<0,05)$.

A textura dos frutos foi medida em dois frutos inteiros com casca, em dois pontos centrais de cada fruto, utilizando-se texturômetro (STEVENS - LFRA texture analyses), com distância de penetração de $10 \mathrm{~mm}$ e velocidade de $2,0 \mathrm{~mm} \mathrm{~s}^{-1}$, utilizando-se ponteiro dTA 9/1000. Os resultados foram expressos em grama-força $\left(\mathrm{gf} \mathrm{cm}^{-2}\right)$.

A acidez titulável foi expressa em gramas de ácido cítrico por $100 \mathrm{~g}$ de polpa, obtida pela titulação de $5 \mathrm{~g}$ de polpa homogeneizada e diluída para 100 $\mathrm{mL}$ de água destilada, com solução padronizada de hidróxido de sódio a $0,1 \mathrm{~N}$, tendo como indicador a fenolftaleína, conforme recomendação do Instituto Adolfo Lutz (1985). Para teor de sólidos solúveis foi determinado com refratômetro digital tipo Palette PR - 32, marca ATAGO, com compensação de temperatura automática (AOAC, 1992) e os resultados expressos em ${ }^{\circ}$ Brix. O pH foi determinado por leitura direta em solução de polpa homogeneizada utilizando-se potenciômetro (Digital DMPH-2), conforme técnica descrita por Pregnolatto e Pregnolatto (1985). O conteúdo de ácido ascórbico foi determinado a partir de $10 \mathrm{~g}$ de polpa, por titulação em ácido oxálico a $0,5 \%$ com 2,6-diclorofenolindofenol (DFI) a $0,01 \mathrm{~N}$, com resultados expressos em $\mathrm{mL}$ de ácido ascórbico 100 $\mathrm{mL}^{-1}$ de polpa (MAPA, 2006). O teor de açúcares solúveis totais foi determinado pelo método descrito por Somogy e adaptado por Nelson (1944) e os resultados expressos em porcentagem (\%).

A extração dos carotenóides totais foi realizada na matéria fresca, segundo o método validado por Sims e Gamon (2002). As leituras foram realizadas na região do visível a 663 (clorofila a), 647 (clorofila b), 537 (antocianina) e 470 (carotenóides) nm. Os valores de absorbância foram convertidos em $\mu \mathrm{g}$ de carotenóides totais $\mathrm{g}^{-1}$.

A atividade da pectinametilesterase (PME) (E.C. 3.1.1.11) foi determinada segundo Hultin, Sun e Bulger (1966). Uma unidade de PME foi definida como a quantidade de enzima capaz de catalisar a desmetilação de pectina correspondente ao consumo de $1 \mathrm{nmol}$ de $\mathrm{NaOH}$ min $^{-1} \mathrm{~g}^{-1}$ de massa fresca, nas condições do ensaio. $\mathrm{O}$ resultado foi expresso em U.E. min $^{-1}$ grama de tecido ${ }^{-1}$. Para determinação da atividade da poligalacturonase (PG) (EC 3.2.1.15) seguiu a metodologia descrita por Pressey e Avants (1982). Uma unidade de atividade da poligalacturonase foi considerada como a quantidade de enzima capaz de catalisar a formação de um nmol de grupos redutores por minuto nas condições do ensaio. Os resultados foram expressos em U.E. min $^{-1}$ grama de tecido ${ }^{-1}$. Os resultados foram submetidos à análise de variância e as médias comparadas pelo teste Tukey $(\mathrm{p}<0,05)$ com auxílio do programa SISVAR. 


\section{Resultados e Discussão}

Os valores de $\mathrm{pH}$ dos frutos de tomate variaram entre 4,27 a 4,37, não sendo influenciados significativamente pelos tratamentos realizados nas plantas, durante a produção dos frutos (Tabela 1). $\mathrm{O} \mathrm{pH}$ pode variar com as condições de cultivo, mas é desejável que esses valores sejam baixos para diminuir a incidência de micro-organismos (CAVASSA; FERREIRA, 2004).
A acidez titulável (AT) em frutos de tomateiro híbrido Giuliana também não apresentou diferença entre os tratamentos avaliados (Tabela 1). Sabe-se que os teores de ácidos orgânicos nos frutos são influenciados por vários fatores, entre eles o estádio de maturação, nutrição e condições climáticas. Após o amadurecimento, durante a colheita e no armazenamento, a quantidade de ácidos orgânicos tende a cair, em função dos processos respiratórios, pois ocorre a oxidação e a conversão destes em açúcares (CHITARRA; CHITARRA, 2005).

Tabela 1. Valores médios de $\mathrm{pH}$, sólidos solúveis (SS, ${ }^{\circ} \mathrm{Brix}$ ), acidez titulável (AT, \% ácido cítrico) e relação SS/AT em frutos de tomate híbrido Giuliana em função dos tratamentos. Botucatu, SP. 2010.

\begin{tabular}{lccccc}
\hline & $\mathrm{pH}$ & $\begin{array}{c}\text { Sólidos solúveis } \\
\left({ }^{\circ} \text { Brix }\right)\end{array}$ & $\begin{array}{c}\text { Acidez titulável }(\% \\
\text { ác.cítrico })\end{array}$ & \multicolumn{2}{c}{ SS/AT } \\
\hline Testemunha & $4,35 \mathrm{~A}$ & $4,08 \mathrm{~B}$ & $0,29 \mathrm{~A}$ & $14,09 \mathrm{~B}$ \\
Piraclostrobina & $4,33 \mathrm{~A}$ & $4,18 \mathrm{~B}$ & $0,31 \mathrm{~A}$ & 13,41 & $\mathrm{~B}$ \\
Boscalida & $4,30 \mathrm{~A}$ & $4,63 \mathrm{AB}$ & $0,30 \mathrm{~A}$ & $15,27 \mathrm{AB}$ \\
Piraclostrobina + Boscalida & $4,32 \mathrm{~A}$ & $4,55 \mathrm{AB}$ & $0,31 \mathrm{~A}$ & $14,68 \mathrm{AB}$ \\
IBA + GA + Cinetina & $4,27 \mathrm{~A}$ & $4,50 \mathrm{AB}$ & $0,30 \mathrm{~A}$ & $15,04 \mathrm{AB}$ \\
GA $_{4+7}+$ benzilaminopurina & $4,32 \mathrm{~A}$ & $5,08 \mathrm{~A}$ & $0,30 \mathrm{~A}$ & $16,98 \mathrm{~A}$ \\
Extrato vegetal & $4,37 \mathrm{~A}$ & $4,33 \mathrm{~B}$ & $0,31 \mathrm{~A}$ & $14,06 \mathrm{~B}$ \\
\hline cv (\%) & $\mathbf{1 , 2 6}$ & $\mathbf{6 , 0 7}$ & $\mathbf{5 , 8 7}$ & $\mathbf{7 , 5 2}$ \\
\hline
\end{tabular}

Médias seguidas de mesma letra na coluna, não diferem significativamente entre si pelo teste Tukey a $5 \%$ de probabilidade.

Fonte: Elaboração dos autores.

O teor de sólidos solúveis (SS), determinado em ${ }^{\circ}$ Brix, é o principal responsável pelo sabor do fruto e pode ser influenciado pela adubação, temperatura, irrigação e, principalmente, pelas características genéticas da cultivar. Os teores de sólidos solúveis variaram em função dos tratamentos, sendo o maior valor de $5,08^{\circ}$ Brix para o tratamento com $\mathrm{GA}_{4+7}$ + benzilaminopurina e o menor para a testemunha com $4,08^{\circ}$ Brix (Tabela 1). Comportamento semelhante foi observado na relação SS/AT, onde o tratamento com o maior valor foi o mesmo para teor de sólidos solúveis, $\mathrm{GA}_{4+7}+$ benzilaminopurina. Segundo Pedro e Ferreira (2005), o balanço entre a acidez e o teor de açúcares, do ponto de vista sensorial, é o responsável pelo sabor característico dos frutos. Um alto valor nessa relação indica uma ótima combinação de açúcares e ácidos que se correlacionam com um sabor suave (CHITARRA; CHITARRA, 2005). O tomate é considerado de excelente qualidade quando apresenta relação de sólidos solúveis/acidez titulável superior a 10 (KADER et al., 1978), fato este observado em todos os tratamentos deste trabalho.

O tratamento com a mistura de piraclostrobina e boscalida apresentou valores superiores de textura indicando fruto mais firme e com melhor conservação pós-colheita (Tabela 2), visto que este foi o tratamento que obteve a menor porcentagem de perda de massa, ao longo do tempo de avaliação (Figura 1). 
Tabela 2. Valores médios de textura $\left(\mathrm{gf} \mathrm{cm}^{-2}\right)$, ácido ascórbico (AA, $\mathrm{mg} 100 \mathrm{~g}^{-1}$ de polpa) e açúcares totais (\%) em frutos de tomate híbrido Giuliana em função dos tratamentos. Botucatu, SP. 2010.

\begin{tabular}{lcrcc}
\hline & $\begin{array}{c}\text { Textura } \\
\left(\mathrm{gf} \mathrm{cm}^{-2}\right)\end{array}$ & $\begin{array}{c}\text { AA } \\
\left(m g ~ 100 ~ ~^{-1}\right)\end{array}$ & Açúcar total (\%) \\
\hline Testemunha & $97,08 \mathrm{ABC}$ & $55,00 \mathrm{~B}$ & $2,90 \mathrm{~A}$ \\
Piraclostrobina & $87,00 \mathrm{BC}$ & $53,75 \mathrm{~B}$ & $2,51 \mathrm{~A}$ \\
Boscalida & $99,33 \mathrm{ABC}$ & $52,00 \mathrm{~B}$ & $2,64 \mathrm{~A}$ \\
Piraclostrobina + Boscalida & $121,67 \mathrm{~A}$ & $61,50 \mathrm{AB}$ & $2,90 \mathrm{~A}$ \\
IBA + GA + Cinetina & $90,75 \mathrm{ABC}$ & $59,25 \mathrm{AB}$ & $2,68 \mathrm{~A}$ \\
GA $_{4+7}+$ benzilaminopurina & $110,50 \mathrm{AB}$ & $72,50 \mathrm{~A}$ & $2,74 \mathrm{~A}$ \\
Extrato vegetal & $76,75 \mathrm{C}$ & $58,25 \mathrm{AB}$ & $2,55 \mathrm{~A}$ \\
\hline cv (\%) & $\mathbf{1 4 , 0 0}$ & $\mathbf{1 2 , 1 6}$ & $\mathbf{1 1 , 0 9}$ \\
\hline
\end{tabular}

Médias seguidas de mesma letra na coluna, não diferem significativamente entre si pelo teste Tukey a 5\% de probabilidade.

Fonte: Elaboração dos autores.

Figura 1. Perda de massa (\%) de frutos de tomate híbrido Giuliana em função dos tratamentos. Botucatu, SP. 2010.

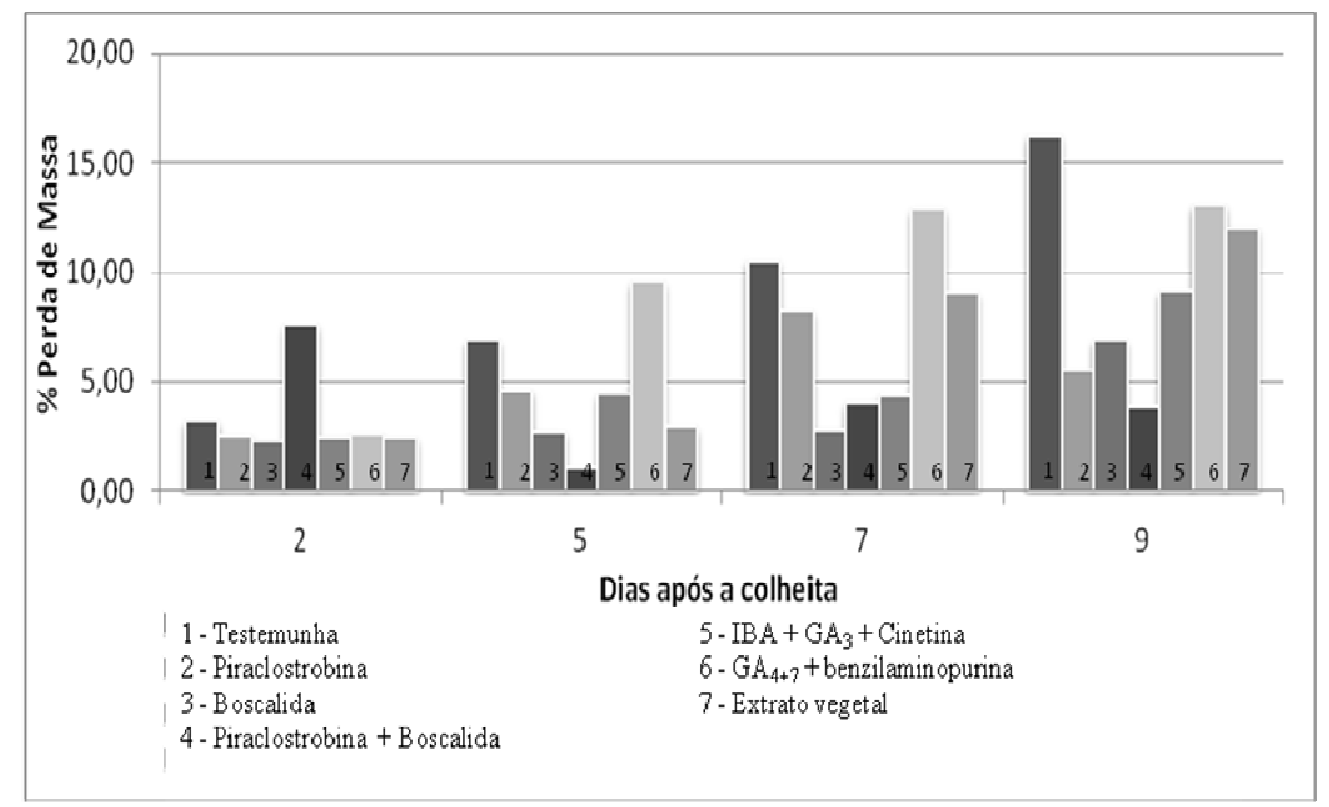

Fonte: Elaboração dos autores.

Na análise do teor de ácido ascórbico, não houve diferenças significativas entre os tratamentos, piraclostrobina + boscalida; IBA $+\mathrm{GA}_{3}+$ Cinetina; extrato vegetal e $\mathrm{GA}_{4+7}+$ benzilaminopurina, porém este último tratamento obteve o maior valor numérico, sendo $31,82 \%$ superior à testemunha (Tabela 2).

Os teores de açúcares solúveis totais não variaram em função dos tratamentos, evidenciando que os produtos utilizados nos tratamentos não interferem nessa característica (Tabela 2). Já a textura e o teor de ácido ascórbico sofreram influência com as aplicações dos diferentes tratamentos.

Os teores de antocianinas foram mais elevados nos tratamento testemunha, boscalida, mistura de boscalida + piraclostrobina, IBA $+\mathrm{GA}_{3}+$ Cinetina e $\mathrm{GA}_{4+7}+$ benzilaminopurina. Para os carotenoides, os tratamentos que foram significativamente superiores foram testemunha, piraclostrobina, mistura de boscalida + piraclostrobina e IBA + 
$\mathrm{GA}_{3}+$ Cinetina. Mostrando que os tratamentos influenciaram na coloração desses frutos (Tabela 3). Os teores de clorofilas a foram influenciados pelos tratamentos testemunha, piraclostrobina, boscalida, mistura de boscalida + piraclostrobina, IBA $+\mathrm{GA}_{3}$ + Cinetina e $\mathrm{GA}_{4+7}+$ benzilaminopurina e para clorofila $b$ os tratamentos que diferiram foram a testemunha, boscalida piraclostrobina + boscalida e IBA $+\mathrm{GA}_{3}+$ Cinetina. Segundo Grossmann e Retzlaff (1997), as estrobirulinas (piraclostrobina) proporcionam folhas mais verdes, com maior teor de clorofila, com efeito, também, na síntese de etileno em condições de estresse e senescência no trigo, por meio da redução da atividade da enzima ácido aminociclopropano-carboxílico-sintase (ACC-sintase), inibindo a síntese de etileno, porém isso só foi observado para a clorofila a. Apenas a testemunha e os tratamentos com piraclostrobina + boscalida e IBA $+\mathrm{GA}_{3}+$ Cinetina mostraram diferenças positivas para as análises de clorofila a e b, antocianina e carotenoides, mostrando que os outros produtos influenciaram negativamente essas características. As baixas concentrações de etileno, diminuem a degradação das citocininas, retardando a degradação da clorofila, provocando o que é chamado de "efeito verde" (GROSSMANN; RETZLAFF, 1997; YPEMA; GOLD, 1999).

Tabela 3. Valores médios de clorofila a (ug g $\left.\mathrm{g}^{-1}\right)$, clorofila $\mathrm{b}\left(\mathrm{ug} \mathrm{g}^{-1}\right)$, antocianinas (ug g $\left.\mathrm{g}^{-1}\right)$ e carotenóides (ug g $\left.\mathrm{g}^{-1}\right)$ em frutos de tomate híbrido Giuliana em função dos tratamentos. Botucatu, SP. 2010.

\begin{tabular}{lcccccc}
\hline & $\begin{array}{c}\text { Clorofila a } \\
\left(\mathrm{ug} \mathrm{g}^{-1}\right)\end{array}$ & $\begin{array}{c}\text { Clorofila b } \\
\left(\mathrm{ug} \mathrm{g}^{-1}\right)\end{array}$ & $\begin{array}{c}\text { Antocianina } \\
\left(\text { ug g }^{-1}\right)\end{array}$ & $\begin{array}{c}\text { Carotenóide } \\
\left(\text { ug g }^{-1}\right)\end{array}$ \\
\hline Testemunha & $31,24 \mathrm{~A}$ & $55,99 \mathrm{~A}$ & $154,63 \mathrm{AB}$ & $39,53 \mathrm{ABC}$ \\
Piraclostrobina & $26,13 \mathrm{AB}$ & $41,44 \mathrm{BC}$ & $127,43 \mathrm{BC}$ & $43,66 \mathrm{AB}$ \\
Boscalida & $28,62 \mathrm{AB}$ & $47,85 \mathrm{AB}$ & $146,32 \mathrm{AB}$ & $32,23 \mathrm{BC}$ \\
Piraclostrobina + Boscalida & $30,56 \mathrm{~A}$ & $49,55 \mathrm{AB}$ & $175,85 \mathrm{~A}$ & $53,30 \mathrm{~A}$ \\
IBA + GA + Cinetina & $34,93 \mathrm{~A}$ & $53,71 \mathrm{AB}$ & $175,00 \mathrm{AB}$ & $40,52 \mathrm{ABC}$ \\
GA $_{4+7}+$ benzilaminopurina & $27,74 \mathrm{AB}$ & $31,40 \mathrm{CD}$ & $136,03 \mathrm{ABC}$ & $36,57 \mathrm{BC}$ \\
Extrato vegetal & $16,58 \mathrm{~B}$ & $26,12 \mathrm{D}$ & $93,59 \mathrm{C}$ & $29,58 \mathrm{C}$ \\
\hline cv (\%) & $\mathbf{1 8 , 7 7}$ & $\mathbf{1 3 , 3 6}$ & $\mathbf{1 4 , 4}$ & $\mathbf{1 5 , 4 1}$ \\
\hline
\end{tabular}

Médias seguidas de mesma letra na coluna, não diferem significativamente entre si pelo teste Tukey a $5 \%$ de probabilidade.

Fonte: Elaboração dos autores.

Os frutos permaneceram por nove dias sobre bancada, com temperatura ambiente em torno de $27^{\circ} \mathrm{C}$ e umidade relativa média de $60 \%$. Ao final desse período, alguns tratamentos ainda apresentavam frutos visualmente bons para $o$ consumo, pois se encontravam firmes e sem sinais de danos fisiológicos ou fitossanitários. O tratamento que mais se destacou na manutenção das características visuais dos frutos de tomateiro foi a mistura de piraclostrobina + boscalida, que apresentou menor perda de massa, seguido pela piraclostrobina e da boscalida (Figura 1).
Observa-se diferenças na atividade das enzimas PME e PG em função da aplicação dos tratamentos. A hidrólise da pectina depende da ação da PME, presente em todos os estádios de desenvolvimento do tomate, porém, sua atividade aumenta durante o amadurecimento (PRESSEY; AVANTS, 1982). Notou-se maior atividade de PME nos tratamentos com boscalida e com a mistura de boscalida e piraclostrobina, 51.581,89 U.E. $\min ^{-1}$ g-1 e 49.696,51 U.E. min $^{-1} \mathrm{~g}^{-1}$, respectivamente (Figuras 2 e 3), sendo estes os tratamentos onde o processo de amadurecimento do fruto iniciou primeiro. 
Figura 2. Atividade da enzima poligalacturonase (PG- U.E./min/g tecido) em frutos de tomate híbrido Giuliana tratados com diferentes produtos químicos. Botucatu, SP. 2010.

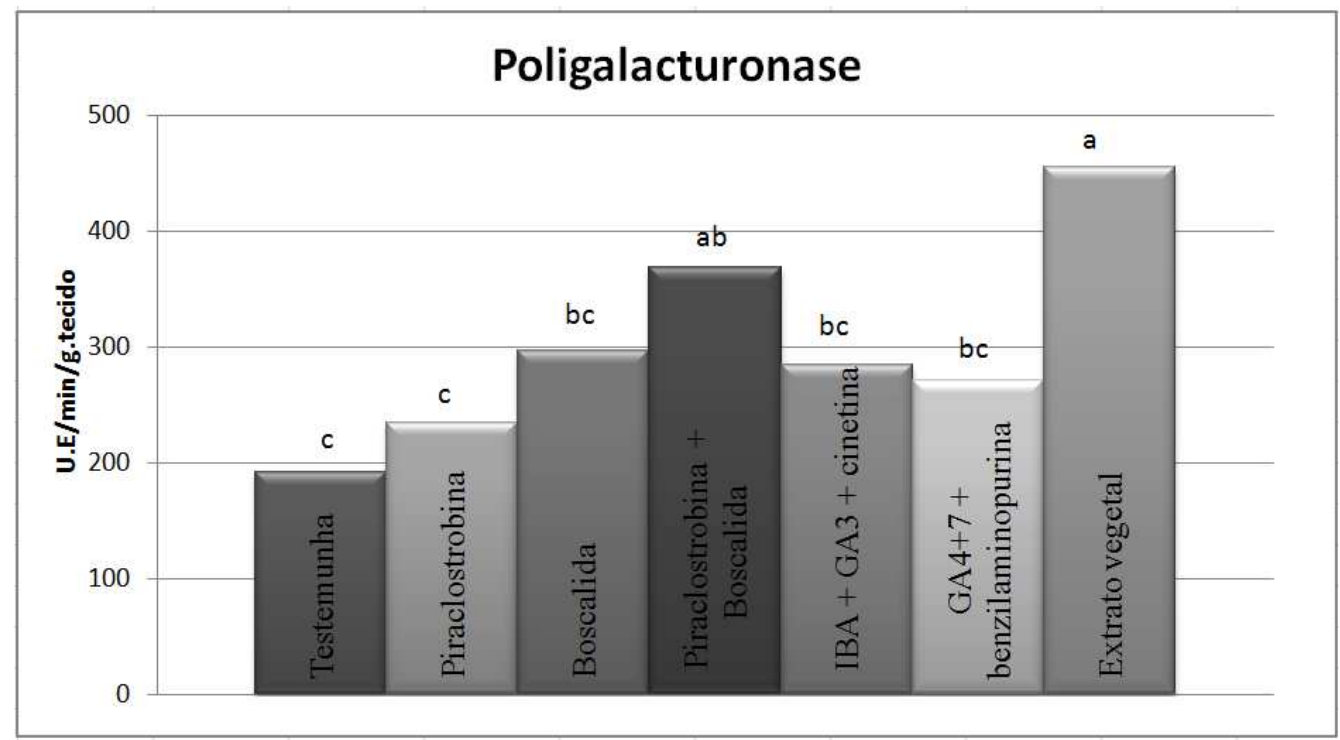

Fonte: Elaboração dos autores.

Figura 3. Atividade da enzima pectinametilesterase (PME- U.E. $/ \mathrm{min} / \mathrm{g}$ tecido) em frutos de tomate híbrido Giuliana tratados com diferentes produtos químicos. Botucatu, SP. 2010.

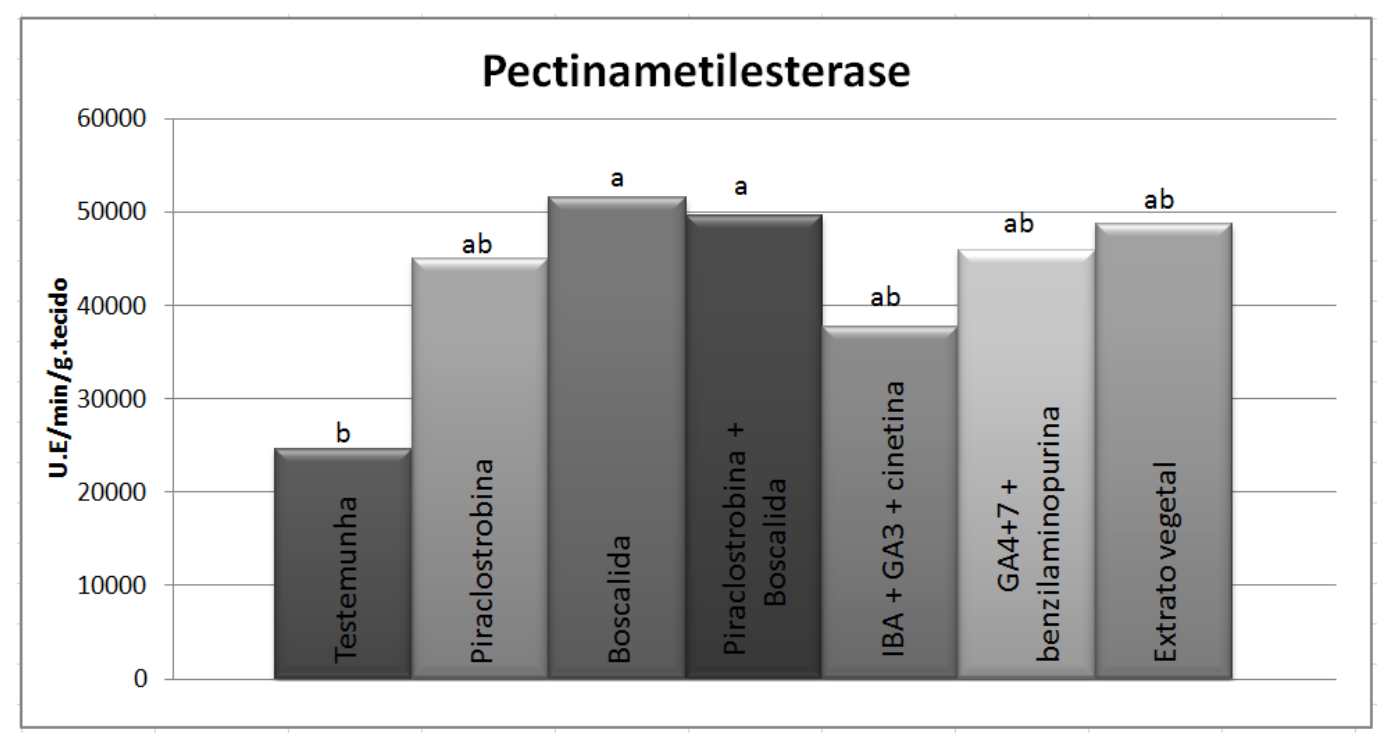

Fonte: Elaboração dos autores.

Ao mesmo tempo, se constatou maior atividade da PG nos tratamentos com extrato vegetal e a mistura de piraclostrobina e boscalida, 455,43 U.E. $\min ^{-1} \mathrm{~g}^{-1}$ e 369,02 U.E. min $^{-1} \mathrm{~g}^{-1}$, respectivamente, indicando que alguns produtos aceleraram o processo de desmetilação das pectinas pela PME (CHITARRA;
CHITARRA, 2005). Essa atividade da PG ocorre durante o amadurecimento, e se correlaciona com aumento de pectinas solúveis e amaciamento durante o amadurecimento (AHRENS; HUBER, 1990). 
$\mathrm{O}$ entendimento da bioquímica do amaciamento de frutos com o amadurecimento poderão propiciar informações comerciais importantes, uma vez que frutos mais firmes poderão ser comercializados por períodos mais longos. Ali et al. (2004) constataram que o início da perda de firmeza dos frutos de carambola, goiaba, banana e mamão foi acompanhada pelo aumento da atividade da PME. Fontes et al. (2008), avaliaram a relação entre a firmeza e a atividade da PME da polpa de mamão cv. Sunrise Solo, e constataram que à medida que a firmeza da polpa decresceu, a atividade da PME aumentou. Nesse experimento foi observada apenas a atividade no momento da colheita dos frutos, não sendo observado o comportamento das enzimas PG e PME ao longo do armazenamento. Podese constatar que nem sempre uma menor firmeza do fruto esteja relacionada a uma maior atividade da enzima PME, já que nesse experimento foi observada uma maior firmeza dos frutos tratados com boscalida. Alguns autores têm mencionado que a PME tem pouca influência no amolecimento do fruto, servindo apenas como ativadora da PG, pois facilita a atividade desta última pela desmetilação das pectinas (BICALHO et al., 2000).

A parcial desmetilação da pectina é necessária antes que a PG possa hidrolisar a PME pode ter a função de preparar o substrato para ser hidrolisado pela PG. A atividade da PME aumenta a atividade da PG, mostrando que a atividade da poligalacturonase é dependente da condição do apoplasto do pericarpo dos frutos (RESENDE et al., 2004).

Nas condições em que o experimento foi conduzido, os resultados obtidos permitiram concluir que a aplicação dos tratamentos não alterou os valores de $\mathrm{pH}$, acidez titulável e açúcares redutores dos frutos. Já os teores de sólidos solúveis, a relação entre sólidos solúveis e acidez titulável e os teores de acido ascórbico mostraram maiores valores para o tratamento com $\mathrm{IBA}+\mathrm{GA}_{3}+$ Cinetina, $\mathrm{GA}_{4+7}+$ benzilaminopurina e a associação entre piraclostrobina e boscalida, que apresentou também menor perda de massa até os nove dias de armazenamento em temperatura ambiente. Além disso, a atividade de PME entre os tratamentos não diferiu estatisticamnete, com exceção da testemunha. A maior atividade da PG nos tratamentos mistura entre piraclostrobina e boscalida e extrato vegetal, indica que alguns produtos aceleram o processo de desmetilação das pectinas pela PME. Portanto a aplicação da mistura de piraclostrobina associado à boscalida melhora a pós-colheita dos frutos de tomate 'Giuliana', assim como os produtos com $\mathrm{IBA}+\mathrm{GA}_{3}+$ Cinetina.

\section{Agradecimentos}

Ao Conselho Nacional de Desenvolvimento Científico e Tecnológico (CNPq) e à Fundação de Amparo à Pesquisa do Estado de São Paulo (FAPESP) pelas bolsas concedidas.

\section{Referências}

ALI, Z. M.; CHIN, L.; MARIMUTHU, M.; LAZAN, H. Low temperature storage and modified atmosphere packaging of carambola fruit and their effects on ripening related texture changes, wall modification and chilling injury symptoms. Postharvest Biology and Technology, Amsterdam, v. 33, n. 2, p. 181-192, 2004.

AHRENS, M. J.; HUBER, D. J. Physiology and firmness determination of ripening tomato fruit.

Physiologia Plantarum, Blacksburg, v. 78, n. 1, p. 8-14, 1990.

ALVARENGA, A. R. A. Valor alimentício. In: ALVARENGA, M. A. R. (Ed.). Tomate: produção em campo, em casa-de-vegetação e em hidroponia. Lavras: Editora UFLA, 2004. p. 27-30.

ASSOCIATION OF OFFICIAL ANALYTICAL CHEMISTRY- AOAC. Official methods of analysis of the association of official analytical chemistry. 11. ed. Washington, 1992. $1015 \mathrm{p}$.

BICALHO, U. O.; CHITARRA, A. B.; CHITARRA, M. I. F.; COELHO, A. H. R. Modificações texturais em mamões submetidos à aplicação pós-colheita de cálcio e embalagem de PVC. Ciência e Agrotecnologia, Lavras, v. 24 , n. 1, p. 136-146, 2000.

CAVASSA, A. C.; FERREIRA, M. D. Conservação pós-colheita de tomates (Lycopersicon esculentum 
Milly.), cv. "Kátia”, utilizando coberturas comestíveis. In: CONGRESSO BRASILEIRO DE ENGENHARIA AGRÍCOLA, 33., 2004, São Paulo. Anais... São Paulo, 2004. p. 1-4.

CHITARRA, M. I. F.; CHITARRA, A. B. Pós-colheita de frutas e hortaliças: fisiologia e manuseio. 2. ed. rev. e ampl. Lavras: UFLA, 2005. 785 p.

FILGUEIRA, F. A. R. Novo manual de olericultura: agrotecnologia moderna na produção e comercialização de hortaliças. Viçosa, MG: UFV, 2000.

FONTES, R. V.; SANTOS, M. P.; FALGUETO, A. R.; SILVA, D. M. Atividade da pectinametilesterase e sua relação com a perda de firmeza da polpa de mamão cv. Sunrise solo e Tainung. Revista Brasileira de Fruticultura, Jaboticabal, v. 30, n. 1, p. 54-58, mar. 2008.

GROSSMANN, K.; RETZLAFF, G. Bioregulatory effects of fungicidal strobilurin kresoxim-methyl in wheat (Triticum aestivum). Pesticide Science, Oxford, v. 50, n. 1, p. 11-20, 1997.

HULTIN, H. O.; SUN, B.; BULGER, J. Pectin methyl esterases of the banana: purification and properties. Journal of Food Science, Chicago, v. 31, n. 3, p. 320327, may/june 1966.

BRACKMANN, A.; GIEHL, R. F. H.; EISERMANN, A. C.; WEBER, A.; HELDWEIN, A. B. Inibição da ação do etileno e temperatura de armazenamento no padrão de amadurecimento de tomates. Ciência Rural, Santa Maria, v. 39, n. 6, p. 1688-1694, set. 2009.

INSTITUTO ADOLFO LUTZ - IAL. Normas analíticas do Instituto Adolfo Lutz: métodos químicos e físicos para análise de alimentos. 3. ed. São Paulo: Instituto Adolfo Luiz, 1985. v. 1.

JUNQUEIRA, A. H.; LUENGO, R. F. A. Mercados diferenciados de hortaliças. Horticultura Brasileira, Brasilia, v. 18, n. 2, p. 95-99, 2000.

KADER, A. A.; MORRIS, L. L.; STEVENS, M. A.; ALBRIGHT-HOLTON, M. Composition and flavor quality of fresh market tomatoes as influenced by some postharvest handling prodecures. Journal of the American Society for Horticultural Science, Alexandria, v. 103, n. 1, p. 6-13, 1978.

KÖHLE, H.; GROSSMANN, K.; JABS, T.; GERHARD, M; KAISER, W.; GLAAB, J.; CONRATH, U.; SEEHAUS, K.; HERMS, S. Physiological effects of strobilurin fungicide F 500 on plants. Biochemical Society Transactions, Londres, v. 22, p. 65, 1994.

LUENGO, R. F. A.; MOITA, A. W.; NASCIMENTO, E. F.; MELO, M. F. Redução de perdas pós-colheita em tomate de mesa acondicionado em três tipos de caixas.
Horticultura Brasileira, Brasília, v. 19, n. 2, p. 151-154, 2001.

MINISTÉRIO DA AGRICULTURA PECUÁRIA E ABASTECIMENTO - MAPA. Métodos oficiais para análises físico-químicas de bebidas e vinagres/ não alcoólicos. 2006. Disponível em: <http://www. agricultura.gov.br/>. Acesso em: 10 nov. 2009.

NELSON, N. A. Photometria adaptation of somogy method for determination of glicose. Journal Biological Chemistry, Baltimore, v. 31, n. 2, p. 159-161, 1944.

PEDRO,A. M. K.; FERREIRA, M. M. C. Non-destructive determination of solids and carotenoids in tomato products by near infrared spectroscopy and multivariate calibration. Analytical Chemistry, Washington, v. 77, n. 8, p. 2505-2511, 2005.

PREGNOLATTO, W.; PREGNOLATTO, N. P. (Coord.). Normas analíticas do Instituto Adolfo Lutz. Métodos químicos e fisicos para análise de alimentos. 3. ed. São Paulo: Instituto Adolfo Lutz, 1985.

PRESSEY, R.; AVANTS, J. K. Solubilization of cell walls by tomato polygalacturonase: effects of pectinesterases. Journal of Food Biochemistry, Gainesville, v. 1, n. 6, p. 57-74, 1982.

RESENDE, J. M.; CHITARRA, M. I. F.; MALUF, W. R.; CHITARRA, A. B.; SAGGIN JNIOR, O. J. Atividade de enzimas pectinametilesterase e poligalacturonase durante o madurecimento de tomates do grupo multilocular. Horticultura Brasileira, Brasília, v. 22, n. 2, p. 206-212, abr./jun. 2004.

SIMS, D. A.; GAMON, J. A. Relationships between leaf pigment content and spectral reflectance across a wide range of species, leaf structures and developmental stages. Remote Sensing of Environment, St. Paul, v. 81, n. 2-3, p. 337-354, 2002.

SOUZA LEÃO, P. C. de; SILVA, D. J.; SILVA, E. G. da. Efeito do ácido giberélico, do bioestimulante crop set e do anelamento na produção e na qualidade da uva 'Thompson Seedless' no vale do São Francisco. Revista Brasileira de Fruticultura, Jaboticabal, v. 27, n. 3, p. 418-421, dez. 2005.

TAIZ, L.; ZEIGER, E. Fisiologia vegetal. Porto Alegre, Artmed, 2009. 719 p.

VILELA, N. J.; MACEDO, M. M. C. Fluxo de poder no agronegócio: o caso das hortaliças. Horticultura Brasileira, Brasília, v. 18, n. 2, p. 88-94, 2000.

YPEMA, H. L.; GOLD, R. E. Kresoxym-methyl modification of a naturally occurring compound to produce a new fungicide. Plant Disease, Saint Paul, v. 83 , n. 1, p. 4-19, 1999. 